\title{
O Sinaes em seu processo de implementação: desafios e perspectivas
}

\begin{abstract}
Resumo: O artigo narra uma "história vivida" acerca do Sistema Nacional de Avaliação de Educação Superior durante praticamente todo o período de sua implementação. Discute a sua pré-história, a instalação da Comissão Nacional de Avaliação da Educação Superior, a consolidação do sistema nacional e a revisão dos instrumentos utilizados. A análise revela que o Brasil já começa a ter uma cultura avaliativa. Conclui que são necessários ajustes naquilo que foi inicialmente pensado e que é preciso definir os próximos passos a serem tomados. Argumenta, neste sentido, que embora a avaliação deva ser o referencial básico para a regulação, isso não significa que ela deve restringir-se a alimentar a regulação apenas.
\end{abstract}

Palavras-chave:
Sérgio Roberto Kieling Franco Doutor em Educação. Professor Associado da Universidade Federal do Rio Grande do Sul. Presidente da CONAES por quatro mandatos.

\section{Introdução}

Este artigo não se constitui como um tratado exaustivo acerca do Sistema Nacional de Avaliação de Educação Superior (Sinaes), mas como um exercício de memória e reflexão de alguém que esteve presente em praticamente todo o período de implementação do Sistema. Por isso, inspirado em Martin Fierro (personagem do folclore gaúcho), que diz que "o diabo sabe por ser diabo, mas sabe mais por ser velho", ele está construído como uma narrativa de uma história vivida.

\section{A pré-história do Sinaes}

Como qualquer acontecimento na História, o Sinaes não é fruto de geração espontânea, nem nasceu simplesmente da ideia genial de alguma pessoa ou de um grupo de pessoas sem ter sido influenciado por uma série de acontecimentos anteriores ou simultâneos. É, pois, preciso ter presente que a história da avaliação da educação superior no Brasil não nasce com o Sistema Nacional criado pela Lei $n^{\circ} 10.861$ de 14 de abril de 2004. É difícil precisar quando ela começa. Como dizem os dialéticos, a História é uma espiral sem fim e sem começo absolutos. No entanto, cabe destacar, no rol de acontecimentos que dão condições à criação do Sinaes, alguns antecedentes. Um deles é o Programa de Avaliação da Reforma Universitária (PARU), tentativa de implementar um 
processo de avaliação das instituições de ensino superior a partir da nova conjuntura surgida com a chamada Reforma Universitária de 1968. Outro fato, este extremamente marcante na própria concepção do Sinaes, é o Programa de Avaliação Institucional das Universidades Brasileiras (PAIUB). Este Programa tem um papel central nesse processo todo, pois é o grande momento de reflexão e de proposição de um processo avaliativo nas universidades brasileiras, que inclusive contagia todo o continente. Toda a América Latina tem no PAIUB uma inspiração muito grande de como fazer um processo de avaliação da educação superior, assim como muito dos princípios do Sinaes já estavam semeados no PAIUB. Não só boa parte das ideias e concepções desse programa estão presentes no atual sistema, como também alguns de seus protagonistas foram essenciais na concepção do Sinaes, como Hélgio Trindade, José Dias Sobrinho, Dilvo Ristoff, Silke Weber e Denise Leite, entre outros. A diferença primordial entre os dois processos é que, enquanto o PAIUB era um movimento basicamente voluntário das instituições de ensino Superior (IES), o Sinaes é um sistema legalmente organizado e com execução estatal.

Na década de 1990 é implantado um processo de avaliação de cursos executado pelo Estado Brasileiro. Trata-se de uma visão, na época bastante contestada, de avaliar os cursos a partir do desempenho dos estudantes em uma prova de conhecimentos relativos aos seus cursos. Foi o Exame Nacional de Cursos (ENC), conhecido popularmente (e internacionalmente) como "Provão". Paralelamente a esse processo a Secretaria de Educação Superior do Ministério da Educação (SESu/MEC) passou a promover a chamada Avaliação das Condições de Oferta, também denominada Avaliação das Condições de Ensino, para a qual chamou professores de todas as áreas para que, através de visitas avaliassem, como o próprio nome diz, as condições para um curso superior funcionar. Essas avaliações serviam para a tomada de decisão a respeito da autorização de cursos novos (resultando na possibilidade legal de sua oferta por uma instituição de ensino superior, caso essa não gozasse de autonomia universitária) ou para o seu reconhecimento oficial, o que confere legalidade ao diploma emitido.

Veja-se que nesse momento a avaliação está completamente atrelada ao processo regulatório, algo tipicamente brasileiro. Embora, mundo afora, os países estivessem a criar agências de acreditação, que faziam avaliações de cursos e instituições para 
atestar o nível de qualidade, sem necessariamente seu resultado dizer respeito ao status legal do curso ou da IES, o Brasil caminhava para um processo mais legalista. Isso se explica, em boa parte, pela política, assumida durante esse período, de expansão da oferta de ensino superior calcado basicamente nas instituições privadas, que, se entendia, precisavam de algum controle para evitar desvios. Tudo coerente com o que preconiza a Constituição de 1988 (art. 209), bem como a Lei de Diretrizes e Bases da Educação Nacional de 1996 (Lei nº 9394, arts. 7oㅗㅇㅡo, 46, 54 e 80)

Em 2000, a função de promover essa avaliação, foi repassada da Secretaria de Educação Superior do MEC (SESu) ao Instituto Nacional de Estudos e Pesquisas Educacionais Anísio Teixeira (Inep), passando esse Instituto a ter prerrogativas que o aproximavam das agências de avaliação, mas que ainda o mantinham distante por ser encarado como um executor de uma política ministerial, basicamente regulatória.

Em 2003, com o início do Governo Lula, tendo à frente do Ministério da Educação o professor Cristóvam Buarque, ao qual foi proposto, pelo próprio Presidente, seguir em frente com o que o MEC já vinha fazendo, "apenas com um desvio à esquerda", iniciou-se um trabalho de discussão para a implementação de um processo mais rico e ao mesmo tempo rigoroso de avaliação da educação superior. Por isso foi instituída a Comissão Especial de Avaliação (CEA) composta pelos professores Dilvo Ilvo Ristoff (UFSC), Edson Nunes (UCAM), Hélgio Trindade (UFRGS), Isaac Roitman (Capes), Isaura Belloni (UnB), José Ederaldo Queiroz Telles (UFPR), José Geraldo de Sousa Júnior (SESu), José Marcelino de Rezende Pinto (Inep), Júlio César Godoy Bertolin (UPF), Maria Amélia Sabbag Zainko (UFPR), Maria Beatriz Moreira Luce (UFRGS), Maria Isabel da Cunha (Unisinos), Maria José Jackson Costa (UFPA), Mario Portugal Pederneiras (SESu), Nelson Cardoso Amaral (UFG), Raimundo Luiz Silva Araújo (Inep), Ricardo Martins (UnB), Silke Weber (UFPE), Stela Maria Meneghel (Furb) e pelos estudantes Giliate Coelho Neto, Fabiana de Souza Costa e Rodrigo da Silva Pereira, representando a União Nacional de Estudantes (UNE). Daniel Ximenes foi o coordenador executivo, assessorado por Adalberto Carvalho, ambos da SESu, e contou ainda com a colaboração especial de Teófilo Bacha Filho do Conselho Estadual de Educação do Paraná. (BRASIL, 2004) 
Essa Comissão propôs a criação de um sistema, inicialmente chamado PAIDEIA, o qual foi apresentado na forma de uma Medida Provisória ao Congresso Nacional. Tal estratégia causou um grande mal estar, por apontar para uma proposição com ranço autoritário (mais pelo método que pelo conteúdo). Após a nomeação de Tarso Genro para o Ministério da Educação, no lugar do Ministro Cristóvam Buarque, a Medida Provisória foi substituída por um Projeto de Lei (escrito às pressas), mas mantendo os princípios exarados pela CEA, no qual era proposto o Sinaes.

A observação de que foi um projeto escrito às pressas não é gratuita. É a essa pressa que devem ser atribuídas certos problemas de redação da Lei, que faz algumas confusões entre as atribuições avaliativas de um Sistema Nacional de Avaliação e as funções regulatórias distribuídas entre o Sistema Federal de Educação e os Sistemas Estaduais.

Um dado interessante é que o Projeto de Lei teve uma passagem muito rápida pelo Legislativo e, graças ao empenho de parlamentares da oposição, não houve resistências maiores e ele foi aprovado por unanimidade, algo difícil de crer levando-se em conta que se tratava de um Governo de esquerda, com fortes resistências frente a todas suas propostas, visto com desconfiança interna e externamente, e sem maioria no Parlamento. Veja-se que a questão da qualidade da educação é algo que já estava muito marcado no pensamento nacional.

Imediatamente após a aprovação da Lei (que recebeu o número 10.861), mais precisamente em maio de 2004, foi constituído um Grupo de Trabalho no Ministério da Educação para propor a regulamentação da mesma e a consequente criação da Comissão Nacional de Avaliação da Educação Superior, a Conaes, que deveria ser o órgão a coordenar o novo Sistema. Já se notava nas discussões desse grupo que o tema não seria simples, uma vez que, embora a lei já traçasse a direção exata, havia divergências no entendimento do processo de execução.

\section{A instalação da Conaes}

Quando da instalação da Comissão Nacional de Avaliação da Educação Superior (Conaes), ocorrida no dia 16 de junho de 2004, com a presença do ministro Tarso Genro, foi eleito seu presidente o professor Hélgio Trindade. Tinha-se aí o desafio de encontrar 
o caminho de execução do Sinaes e, principalmente implantar uma cultura de avaliação, até o momento tão ausente no modus vivendi brasileiro.

O Sinaes dava continuidade, de certo modo a algumas práticas avaliativas que já vinham se consolidando. Uma delas era a avaliação de desempenho dos estudantes (através do Exame Nacional de Desempenho de Estudantes - Enade), que não deixava de ser um processo que partia da experiência do Provão, ainda que sob novas diretrizes. A outra continuidade era a avaliação de cursos, que tinha a precedência das avaliações das condições de ensino. No entanto, a grande novidade era a avaliação de instituições, por isso tratou-se logo de mobilizar as IES para a criação das Comissões Próprias de Avaliação (CPA), organismo criado pela Lei do Sinaes, e que deveria se ocupar dos processos avaliativos no interior das IES. Por isso os primeiros trabalhos assumidos concretamente estavam voltados à autoavaliação institucional. Logo foram elaboradas orientações para a avaliação institucional e foi feita uma grande mobilização, no país inteiro, através de seminários, para orientar a criação das CPA e disparar os processos de autoavaliação, ou seja, uma mobilização intensa para preparar a sociedade e a comunidade das instituições de ensino brasileiras a pensar a avaliação institucional.

Esta primeira mobilização já evidenciou o problema da operacionalidade. Afinal, a Conaes foi concebida para coordenar e supervisionar o Sistema, mas o trabalho para sua implantação exigia ações concretas. Assim foi-se construindo, o fazer à medida que os desafios se apresentavam. A Conaes foi trabalhando com as CPA, inclusive elaborando o manual para a autoavaliação institucional. O Inep, com agilidade, e com toda a prática que tinha com o Exame Nacional de Cursos, faz a reformulação deste para a implementação do Enade.

Além disso tudo, um desafio importantíssimo era criar os instrumentos de avaliação. O Inep inicia esse trabalho de construção dos instrumentos de avaliação de cursos e de instituições, partindo da experiência já acumulada nas avaliações que vinham ocorrendo.

O instrumento de avaliação de instituições era a grande novidade, mas se inspirava nos instrumentos utilizados para credenciamento de novas instituições. Um desafio importante era contemplar as dez dimensões avaliativas determinadas pela Lei e ao mesmo tempo definir o que se aproveitaria dos instrumentos e dos sistemas já existentes. Foi criado um grupo com integrantes da Conaes, do 
Inep, além de consultores externos, para a elaboração do referido instrumento. Não foi tarefa fácil, pois como é comum afirmar-se na literatura sobre avaliação, todos propõem a qualidade, mas não há unanimidade na concepção do que seja qualidade.

Paralelamente, também, foi proposta a criação de um grupo para a construção do instrumento de avaliação de cursos. A ideia que se defendia na Conaes era que fosse elaborado um único instrumento para todos os cursos, mas ao mesmo tempo havia a defesa de que os instrumentos deveriam atender as especificidades de cada curso. Nesse momento instalou-se também uma polêmica teórica. A Lei do Sinaes falava de "dimensões do Sinaes" ao se referir às dez dimensões da avaliação institucional. Já sobre a avaliação de cursos ela se refere a "identificar as condições de ensino oferecidas aos estudantes, em especial as relativas ao perfil do corpo docente, às instalações físicas e à organização didático-pedagógica", e logo depois afirma que a atribuição dos conceitos nessa avaliação será "a cada uma das dimensões e ao conjunto das dimensões avaliadas". Portanto, a avaliação de cursos deveria se ocupar dos aspectos organização didático-pedagógica, corpo docente e infraestrutura e ao mesmo tempo referir-se às dez dimensões do Sinaes? Outra interpretação, mais pragmática era que os três aspectos eram, de fato, as três dimensões da avaliação dos cursos. Foi uma discussão interessante do ponto de vista teórico, mas que pouco avançou na época. Hoje se tem clareza que as dimensões da avaliação institucional devem perpassar todo o processo de avaliação, mas não há como avaliar um curso a partir das dez dimensões. Apesar da aparente inutilidade dessa discussão, ela foi fundante da compreensão de que essas avaliações preconizadas no Sinaes devem estar muito bem articuladas.

Tanto a discussão de conteúdo, como a execução das ações programadas, fizeram emergir o problema de definição de papéis. Até onde ia o papel da Conaes e como o Inep ficava no cenário? Desde que o Inep assumira as funções de promover a avaliação, ele havia passado a exercer um papel muito próximo a uma agência de avaliação. Por outro lado, como a Lei do Sinaes criara a Conaes como um órgão coordenador e supervisor do processo, entendia-se que esta deveria ser a cabeça do sistema e o Inep os membros. Tal dicotomia foi criadora de muita tensão.

Analisando mais de longe, pode-se concluir que a Lei n ${ }^{\circ} 10.861$ não criara uma agência de avaliação, estratégia adotada pela maio- 
ria dos países ao implantar seus sistemas de avaliação, mas criara uma rede, que, no seu conjunto, faz as vezes de uma agência. Neste sentido, não se pode pensar o Sinaes somente com a Conaes, nem somente com o Inep, nem simplesmente a associação dos dois órgãos, na dicotomia expressa antes, mas o trabalho coordenado dessas duas instâncias e ainda em articulação com os órgãos do Ministério da Educação. Dever-se-ia somar ainda a participação do CNE, que é figura ausente no texto da lei, mas que o Decreto $n^{\circ}$ 5.773 de 2006 fez muito bem em destacá-lo, além dos órgãos dos sistemas estaduais de educação. Em todo o caso, ficou patente que não havia um desenho claro de como era a distribuição de papéis. E isso, obviamente gerou um certo conflito, mas o conflito é importante para a promoção dos avanços.

Chegou a ser feita uma consulta à Consultoria Jurídica do Ministério da Educação a respeito dos limites de ação da Conaes, o que até aumentou o mal estar. Como será visto no decorrer do presente texto, a definição de papéis é um processo que vai ocorrendo à medida que as ações vão se desenrolando.

Em meio a todo esse processo dinâmico, e até tenso, era necessário fazer o Sistema andar. As IES começaram a produzir relatórios de autoavaliação, que foram enviados à Conaes. Esta realizou um processo de análise dos relatórios para dar um feed back sobre sua consistência. Mas ainda não se tinha conseguido definir como o Inep deveria proceder a avaliação. Havia, ademais, um represamento grande de processos de autorização de cursos. Para tanto o Inep solicitou à Conaes que priorizasse as avaliações de autorizações de cursos. Compreendendo a urgência disso, foi dada anuência para essa estratégia. Isso resultou em um atraso maior ainda da avaliação dos cursos e instituições no prisma do Sinaes. Embora as autorizações já estivessem com um certo grau de sintonia com o Sistema, já se sabia que as avaliações que interessavam à consolidação do Sinaes eram aquelas dos cursos e das IES que já faziam parte do Sistema de Ensino.

Um processo que também inicia já em 2004 é a aproximação com os sistemas estaduais. Como foi afirmado anteriormente, a Lei que institui o Sinaes tem problemas na redação, especialmente no que se refere à definição de competências do Sistema Federal e dos Sistemas Estaduais e do Distrito Federal. Através de um movimento hábil por parte da Presidência da Conaes e da Presidência do Fórum dos Conselhos Estaduais de Educação, coordenado, 
então, pela professora Nadja Vianna, que mais tarde viria a se tornar Presidente da Conaes, se consegue barrar um movimento pelo questionamento da constitucionalidade da Lei, e se buscar a aproximação de forma a possibilitar que o Sinaes seja realmente Nacional, ou seja, integrando os diferentes Sistemas de Educação. Este processo de aproximação ainda não está terminado, pois esbarra ora em diferentes interpretações do que seja o federalismo, ora na dificuldade de o Ministério da Educação absorver ações necessárias para um regime de colaboração entre os sistemas que faça jus a esse qualificativo.

Paralelamente havia ainda o desafio de qualificar o grupo de avaliadores. Estes haviam sido capacitados e tinham experiência de avaliação antes da implantação do novo Sistema. Por isso era mister capacitá-los e, principalmente, instituir critérios objetivos para a constituição de um banco de avaliadores. O Inep tomou a dianteira de propor a criação de um banco único, que englobasse avaliadores de curso e avaliadores institucionais, mas que ao mesmo tempo normatizasse a relação dos avaliadores com o Sistema. Por isso a Conaes se debruçou num profundo processo de discussão para a constituição dos critérios de composição desse banco. Aqui cabe ressaltar o papel da Capes, dentro da Conaes, para a construção desses critérios.

Criou-se, então o Banco dos Avaliadores do Sistema (Basis) com regras muito bem definidas tanto para a nomeação dos integrantes do banco como para a constituição das comissões de avaliação, que passaram a ser nomeadas a partir de critérios objetivos, sem interferência humana, eliminado assim a possibilidade de manipulação na composição na constituição das comissões, de modo a atender interesses de qualquer parte que seja.

Com os instrumentos aprovados, com o início das avaliações de curso sendo executadas, com algumas avaliações institucionais tendo sido feitas com os novos instrumentos e com uma imensa mobilização por parte das instituições para a sua autoavaliação, estavam dadas as condições para a implementação de fato do Sinaes.

\section{A consolidação do sistema}

Em 2006 o professor Hélgio fora indicado pelo Ministro Fernando Haddad (que em 2005 assumira o Ministério da Educação em substituição ao Ministro Tarso Genro) para assumir uma cadeira no 
Conselho Nacional de Educação, o que the impediria de seguir na Conaes, pois sendo esta uma instância da avaliação, e aquele um órgão regulador, seria incoerente ocupar as duas posições.

Era um ganho para o CNE passar a contar com alguém com a reflexão e com a vivência do Sinaes, mas ao mesmo tempo era uma perda para a Conaes ter de abrir mão do líder do processo de implementação. Seu mandato de presidente estava chegando ao fim (já havia sido reconduzido uma vez), mas seu mandato como membro ainda não havia se esgotado.

Com a saída do professor Hélgio, e também coincidindo com o término dos mandatos de alguns membros, era o momento de fazer uma renovação expressiva do quadro da Conaes. Por coincidência também o Inep passara há pouco tempo pela mudança de sua presidência. Assim, em 2006 é eleito para a Presidência da Conaes, uma vez que já havia participado dela como representante da Secretaria de Educação a Distância e agora havia sido indicado como membro de notório saber, o professor Sérgio Franco. Uma das primeiras ações dessa nova Presidência fora combinar com o Presidente do Inep que o momento era de trabalharem juntos. Havia a necessidade de se garantir a operacionalidade sem abrir mão de determinados princípios. O sucesso do Sinaes, como sistema, dependia (e ainda depende) do equilíbrio entre as necessidades operacionais, as necessidades políticas e a clareza filosófica, de modo que o sistema não sofresse desvios em função das dificuldades de sua operacionalização, nem se torne inviável pela busca obsessiva da sua perfeição.

Pode-se dizer que o que marcou o terceiro ano da Conaes foi o processo de conciliação. Os diversos atores tinham que encontrar o caminho conjunto e ao mesmo tempo definir seus papéis.

Seguiu-se com o grande desafio da operacionalidade. As diversas dificuldades vividas, até esse momento, resultaram que, ao final do primeiro triênio, praticamente só se tivesse produzido, como resultado, a aplicação do Enade. Por outro lado, viveu-se um processo riquíssimo: a formação das CPA, bem como a capacitação destas e de avaliadores; a criação do Basis; a formulação dos instrumentos de avaliação de cursos e de instituições.

Um passo importante e marcante foi a criação da Comissão Técnica de Acompanhamento da Avaliação (CTAA) como um órgão estabelecido formalmente para os recursos da avaliação, pois 
um bom processo avaliativo precisa ter espaço para revisão dos seus resultados.

Um outro momento importante nesse terceiro ano do Sinaes foi a designação da Conaes como representante do Brasil na Reunião de Agências Nacionais de Acreditação do Mercosul, e portanto ser interlocutora do Brasil no contexto dessa região continental. Assim, a Conaes passou a ser um interlocutor importante para a criação do Sistema de Acreditação Regional de Cursos Universitários do Mercosul (Sistema ARCU-Sul).

No final desse primeiro triênio, o Sinaes e a Conaes já começavam a mostrar a que vieram. Mas ainda o que se tinha era muitos processos e poucos resultados. De fato, era preciso enfrentar o problema da complexidade do processo. Inclusive um articulista, em uma importante revista semanal, afirmou que se havia criado um sistema muito complicado, e que não teria como dar certo. Não se pode negar a complexidade do Sinaes, uma vez que reflete o sistema de educação superior brasileiro, no entanto complexidade é diferente de complicação.

Tal complexidade era clara na dificuldade de execução do conjunto das avaliações do Sinaes. Por isso, após um estudo detalhado, o Inep, através de seu Presidente à época, o professor Reynaldo Fernandes, propõe a criação do Conceito Preliminar de Curso (CPC). O que se queria era algo que pudesse ajudar a dar a desejada agilidade. Tal medida foi cercada de muita polêmica, porque, fazendo o exercício típico da avaliação, tem fortalezas e fragilidades. São fortalezas do CPC: a praticidade, a agilidade na chegada ao resultado, a coerência com o Enade, que pode ser também uma fragilidade, porque, afinal, a avaliação do curso in loco, está centrada mais nos processos (em todo o caso, um bom curso deve ter bons resultados). Isso tudo confere uma clareza maior para a sociedade em geral. Claro que o jeito mais fácil de traduzir para a sociedade é fazendo rankings, que foi o que a imprensa imediatamente fez. Mas isso já é outro problema.

O CPC tem também fragilidades. A primeira fragilidade é na verdade uma dúvida: será que o CPC guarda coerência com o conceito de uma avaliação in loco? Algo que o CPC trouxe como uma grande vantagem, mas que também é uma desvantagem foi a dispensa das avaliações. Quando se dispensou as avaliações dos cursos que tinham alto CPC, perdeu-se a noção de como funcionam os cursos bons. Passou-se a ter somente dados de avaliação in 
loco de cursos com problemas. Está certo que, no reconhecimento de curso se avalia todos, mas os cursos que já estavam em andamento, que já haviam se consolidado, passaram a ficar de fora do processo. Há ainda a questão que se coloca atualmente: afinal o Conceito Preliminar é preliminar ou é perene? Hoje se tem muita clareza de que o CPC não mede exatamente a mesma coisa que a avaliação in loco. Portanto, para efeito de avaliação ele se trata de um conceito realmente preliminar, no entanto a regulação pode considerá-lo como um indicador, e, neste sentido, seu significado é mais perene.

Na esteira dessa discussão toda, surge a proposição do Índice Geral de Cursos, o IGC. Esta foi uma discussão muito grande. Poder-se-ia criar um conceito preliminar de instituição? Será que os dados que se tem a partir dos CPC e das avaliações da Capes podem servir para prever a qualidade institucional? A conclusão que se chega é que se trata de medidas muito diferentes. Se há aproximações possíveis entre o CPC e a avaliação de cursos, que mesmo assim tem seu lado discutível, a distância entre o IGC e a avaliação institucional era grande demais. Então a posição da Conaes foi que o Ministério podia (e devia) criar seus indicadores, mas que o IGC não seria um conceito do Sinaes. E por isso que o nome proposto foi de um "Índice Geral de Cursos", porque é isso que ele faz: uma medida geral dos cursos. É um indicador interessante, mas é importante saber onde colocá-lo. Aliás, esse é o grande problema dos indicadores: saber onde colocá-los.

\section{A revisão dos instrumentos (primeira parte)}

Na passagem de 2006 para 2007, começou-se a executar a primeira revisão dos instrumentos. Percebeu-se que eram feitas maquiagens nas instituições e cursos para receberem as comissões de avaliação. Qualquer instrumento que fica muito tempo em vigor dá margem a isso. Assim começou-se a buscar formas de evitar a maquiagem, de aumentar o peso do avaliador na decisão, e se cunhou um conceito muito importante, que foi o de "referencial mínimo de qualidade". A ideia de que o conceito 3 tinha que estar muito bem estabelecido para que se possa dizer bem claro o que se vai considerar mínimo de qualidade. Não o mínimo dos mínimos, mas o mínimo da qualidade que se deseja. E começa, a discussão 
de que tendo um mínimo de qualidade, é necessário ir apontando para algum caminho de excelência.

No âmbito dessa discussão, envolvendo as secretarias do MEC, envolvendo outros atores, comissões que o Inep chamava, vem a busca da definição mais clara do que vem a ser o ciclo avaliativo, que o Decreto $n^{0} 5.773 / 2006$ já trazia. E aí se definiu bem claramente que o ciclo avaliativo se refere àquilo que vinha sendo tratado de "avaliação para fins de renovação de reconhecimento". E se conseguiu inverter o processo de maneira muito interessante. O pequeno ato de tirar do instrumento a expressão "avaliação para fins de renovação de reconhecimento" e passar a constar "avaliação do ciclo do Sinaes", muda significativamente o prisma para o avaliador e para a instituição que está sendo avaliada.

Outro avanço importante foi a ideia, colocada na Portaria Normativa 1, que depois foi transformada na Portaria Normativa 40, de que o ciclo é disparado pelo Enade. (BRASIL, 2009, 2010) Isso teve um outro impacto simbólico muito importante: o que dispara o processo não é mais o ato regulatório, mas a avaliação. No entanto, as avaliações ainda não estão calibradas. O peso do Enade ainda está muito grande, mas já se começa a selar que a dinâmica da avaliação não é exatamente a mesma dinâmica da regulação.

Ao ser feita a revisão dos instrumentos do ciclo (de cursos e de instituições) também se fez a revisão dos instrumentos de autorização e de reconhecimento. Ou seja, o ciclo do Sinaes tem um tratamento. Já a entrada no sistema, que é a autorização e o reconhecimento, tem outra dinâmica. Isso sem deixar de lado uma preocupação importante com relação a três cursos em especial, que eram a Pedagogia, o Direito e a Medicina. Por isso foram definidos instrumentos diferenciados para esses cursos na autorização e reconhecimento.

Em 2007 acontecem, maciçamente, as avaliações institucionais. Um momento muito especial e que gerou outra discussão muito importante. O resultado das avaliações institucionais mostrou um outro aspecto desse sistema de educação superior sui generis, que é o brasileiro. As instituições tidas como melhores não se saem bem na avaliação institucional. Na avaliação institucional, analisa-se principalmente como é a gestão, e as instituições mais tradicionais, no Brasil, não costumam ter boa gestão. Elas têm tradição de qualidade, mas a gestão é complicada. Isso se refere principalmente às instituições públicas, mas também se aplica às 
grandes instituições privadas tradicionais, principalmente universidades confessionais e comunitárias, com existência já de 40 ou 50 anos, porque fazer qualidade na educação superior tem a ver com certos processos históricos. Os fatos de se conseguir trazer bons professores, ter vestibulares competitivos, ajudam a dar qualidade. Também há de se levar em conta que se trata daquelas IES que inauguraram a pós-graduação no Brasil e, portanto, a qualidade está presente em seu seio. Mesmo assim, a gerência dessa qualidade é um problema.

Nesse período também se tomou uma decisão: parar de avaliar a entrada do sistema e passar avaliar o ciclo e isso trouxe finalmente o primeiro ciclo completo do Sinaes, com avaliação de instituições, de cursos e do desempenho dos estudantes. Ciclo não totalmente fechado pelo simples fato de que ele nunca vai ser totalmente fechado. Porque sempre há recursos das avaliações, e quando se trata de avaliações caso a caso, os processos não ocorrem simultaneamente. As dinâmicas vão acontecer, mas já se tem o conjunto das três avaliações, ou melhor, das duas avaliações: das instituições e dos cursos (porque o desempenho dos estudantes é uma avaliação do curso e não do estudante).

Em 2008, assume a Presidência da Conaes, a professora Nadja Valverde Vianna, que já vinha compondo a Conaes desde 2006. Seu trabalho dá continuidade a todo esse processo. Junto com isso, vem a consolidação da CTAA, tendo cada vez mais clareza do seu papel e também se começa a discussão de como deve ser a avaliação dos cursos a distância. Tratava-se de um tema que a Conaes vinha preocupada mas que a Secretaria de Educação a Distância (SEED), que existia na época, tinha sérias resistências, até porque não sabia exatamente como fazer essa avaliação.

\section{A revisão dos instrumentos (segunda parte)}

O amadurecimento dessas questões, a prática das avaliações, as comparações de seus resultados, bem como a análise dos processos recursais, levou a Conaes a promover uma nova revisão dos instrumentos. Considerando-se o fato de que, em seis anos, promoveu-se a elaboração dos instrumentos e duas revisões dos mesmos, poder-se-ia ficar com a impressão de que não se sabia para onde se caminhava. O interessante é que a reação das instituições 
foi bem diferente. Havia o entendimento de que se trata de um processo de aperfeiçoamento necessário.

Notou-se a necessidade de dar mais coesão entre as avaliações. Ter mais coerência e congruência entre os vários aspectos que se está medindo. Houve questionamentos se tal revisão não seria um afrouxamento, mas está cada vez mais claro que não. A Conaes foi inclusive questionada pela Ordem dos Advogados do Brasil (OAB), se essa revisão dos instrumentos não era uma forma de abrir espaço para dar conta da expansão que se precisa fazer da educação superior, e que está proposta no Plano Nacional de Educação (PNE). A consciência da Conaes era que essa nova revisão dos instrumentos tinha coerência com o PNE, mas no sentido de mostrar que a expansão da educação superior deve ser feita deixando demarcada a qualidade que se quer.

Em 2010, o professor Sérgio Franco retorna à presidência da Conaes. Nesse mesmo ano, o MEC passa por um processo de reestruturação, em que é criada a Secretaria de Regulação da Educação Superior (Seres), que traz um diálogo diferente. Fica demarcada a discussão complementar entre a contribuição da avaliação tanto para a regulação (por conta da Seres) como para a consolidação da política de educação superior (por conta da SESu). Está também lançada a discussão de uma agência reguladora da educação superior.

A Conaes prossegue em seu processo de discussão da revisão dos instrumentos, realizando audiências públicas (um momento muito intenso de aproximação com diversos interlocutores), passando a compreender que esses novos instrumentos não são mais blocos fechados, mas conjuntos de indicadores coerentes, e que o aperfeiçoamento necessário que se fará fazendo o aperfeiçoamento dos indicadores. Entendendo que há indicadores que precisam ser revistos até anualmente, pela dinâmica que se tem no processo, e outros que são mais perenes, e, desse modo, definindo uma prática constante de estudos e acompanhamento da avaliação como um todo, dá-se um passo definitivo para a consolidação do Sinaes.

Em seguida é disparado o processo de revisão do instrumento de avaliação de instituições, na perspectiva de que ele não seria organizado em função das dez dimensões do Sinaes, embora devendo manter coerência com elas. 


\section{Concluindo}

Fazendo um balanço, desses já mais de oito anos, pode-se dizer que o Brasil já começa a ter uma cultura avaliativa, desafio lançado em 2004. Não se tem ainda maturidade na cultura avaliativa, mas já há a consciência de que qualidade sem avaliação não existe.

Um outro aspecto interessante, que se pode ver a partir dessa caminhada, é que as consequências da implementação do Sinaes são diferentes em IES públicas e privadas. Isso vai mostrando que o Sinaes não foi, como se diz em algumas publicações, um sistema para controlar o sistema privado. Claro que são consequências diferentes porque são instituições de natureza diferente, com tradições diferentes.

Já há praticamente um consenso de que se está construindo um processo de qualificação, e portanto, sabe-se qual a direção que se está seguindo. O caminho se faz ao andar, e esse andar já tem orientação. E o fato de já se ter criado um ritmo para a conclusão dos ciclos avaliativos começa a dar condições a algo que é fundamental para a maturidade do sistema avaliativo: a série histórica.

E qual é o futuro? A Conaes tem discutido a relação entre indicadores e avaliação. Precisa ser fortalecida a criação de indicadores, que pode ser feita a partir do Censo da Educação Superior, para que a avaliação possa caminhar cada vez mais independentemente do processo regulatório, ainda que ela alimente o processo regulatório, e este também dê seus retornos para a avaliação. Afinal, está definido que a avaliação deve ser o referencial básico para a regulação, mas isso não significa que ela deva restringir-se basicamente a alimentar a regulação.

Uma certeza se tem: o cenário mudou. E isso deixa a certeza de que é preciso refletir, porque à medida que o cenário vai mudando é necessário ir fazendo os ajustes daquilo que foi pensado e é preciso definir os próximos passos a serem dados. Juntamente com todos os parceiros - Governo, instituições, entidades representativas, sociedade como um todo - se constrói o caminho da consolidação de um Sistema que possa merecer esse qualificativo de Nacional de Avaliação da Educação Superior, promotor de uma educação de qualidade em um país que pretende, e está no caminho de ser, uma potencia mundial, em vários aspectos, quiçá também no aspecto da educação. 


\title{
SINAES implementation process: challenges and perspectives
}

\begin{abstract}
This article presents a narrative of a "lived history" with respect to SINAES of someone who participated in practically the entire period of its implementation. It discusses the pre-history of SINAES, the installation of CONAES, the consolidation of the national system and the revision of the utilized instruments. The analysis reveals that the consequences of SINAES are different for public and private HEI and that Brazil is beginning to create a culture of evaluation. In concluding the article, the author affirms that adjustments must be made in what was originally projected and that it is necessary to define the next steps to be taken. He closes by arguing that although evaluation must be the basic reference for regulation, it should not be restricted to serving regulation exclusively.
\end{abstract}

Key-Words: Assessment, Higher Education, Public Policy.

\section{Referências}

BRASIL. Lei ${ }^{\circ}$ 10.861, de 14 de abril de 2004. Institui o Sistema Nacional de Avaliação da Educação Superior - SINAES e dá outras providências. Diário Oficial da União, Brasília, DF, 15 abr. 2004, p. 3.

BRASIL. SINAES - Sistema Nacional de Avaliação da Educação Superior: da concepção à regulamentação. 2. ed. ampl. Brasília: Instituto Nacional de Estudos e Pesquisas Educacionais Anísio Teixeira, 2004.

BRASIL. Constituição (1988). Constituição da República Federativa do Brasil. Brasília: Senado Federal, 1988.

BRASIL. Lei no 9.394, de 20 de dezembro de 1996. Estabelece as diretrizes e bases da educação nacional. Diário Oficial da União, Brasília, DF, 23 dez. 1996, p. 27833

BRASIL. Decreto n 5.773 , de 9 de maio de 2006. Dispõe sobre o exercício das funções de regulação, supervisão e avaliação de instituições de educação superior e cursos superiores de graduação e seqüenciais no sistema federal de ensino. Diário Oficial da União, Brasília, DF, 10 maio 2006, p. 6

BRASIL. Ministério da Educação. Portaria Normativa 1, de 10 de janeiro de 2007. Estabelece o calendário de avaliações do Ciclo Avaliativo do Sistema Nacional de Avaliação da Educação Superior - SINAES para o triênio 2007/2009. Diário Oficial da União, Brasília, DF, 11 jan. 2007, p. 7

BRASIL. Ministério da Educação. Portaria Normativa 40, de 12 de dezembro de 2007. Diário Oficial da União, Brasília, DF, 29 dez. 2010, p. 23.

BRASIL. Decreto-Lei n ${ }^{\circ}$ 2423, de 7 de abril de 1998. Estabelece critérios para pagamento de gratificações e vantagens pecuniárias aos titulares de cargos e empregos da administração federal direta e autárquica e dá outras providencias. Diário Oficial [da República Federativa do Brasil], Brasília, v. 126, n. 66, p. 6009, 8 abr. 1998. Seção 1, pt1. 
TRINDADE, H. Desafios, institucionalização e imagem pública da CONAES. Brasília: Ministério da Educação, 2006.

Recebido: 14/09/2013 | Aprovado: 11/10/2012 